Available online at www.jmle.org

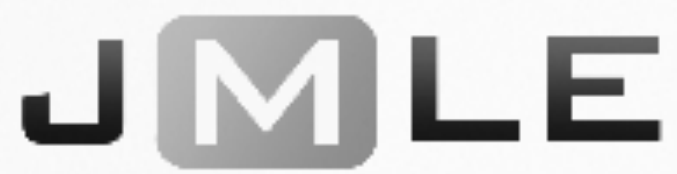

The National Association for Media Literacy Education's

Journal of Media Literacy Education 10 (3), 20 - 42

\title{
Teaching Girls Online Skills: Results of the Wikid Grrls Intervention
}

\author{
Stine Eckert, Wayne State University \\ Jade Metzger-Riftkin Wayne State University \\ Joanna Nurmis University of Maryland, College Park
}

\begin{abstract}
In 2013-2016, we designed and implemented Wikid Grrls, a 10-week after-school workshop series to teach online skills to middle school girls in U.S. schools. We interviewed and surveyed eighty participants before and after the workshop. Girls' online skills and confidence in them increased for the duration of the workshop series. Participants expressed great interest in learning more, but media literacy programs at their schools emphasizing online skills were lacking. Using feminist theories and the reader-to-leader framework, we argue that such media literacy interventions bring immediate learning rewards for participants. Further, we conclude that media literacy classes that include online skills should become regular features in U.S. school curricula instead of being offered merely in voluntary programs. This is essential to narrow gender gaps in digital knowledge creation and sharing. Future research is needed to assess long-term benefits of media literacy interventions to teach online skills longitudinally to see if, and how, such initiatives figure into subsequent schooling and career decisions.
\end{abstract}

Keywords: gender gap, Wikipedia, intervention, feminism, media literacy

A United Nations University study (Glott, Schmidt, \& Ghosh, 2010) found that women are only $12.6 \%$ of Wikipedia contributors (people who edit or write articles). Prompted by Wall Street Journal and New York Times reports, this gender gap has become a salient issue for Wikipedia leaders, who - among other measures - set up a page within Wikipedia to collate scholarship on the encyclopedia's gender biases (Wikipedia, 2016). Additionally, they emphasized increasing the proportion of female contributors to $25 \%$ by 2015 (Cohen, 2011). Despite these efforts, in August of 2014, Wikipedia co-founder Jimmy Wales assessed Wikipedia 
had "completely failed" to fix the gender imbalance (BBC, 2014, para 1). In turn, the platform remains a difficult environment for women (Paling, 2015) and only about $17 \%$ of notable profiles are women (BBC, 2016). This gender imbalance among writers and editors is further reflected in the content, specifically at least 4,400 women scientists meet Wikipedia's standards for notability yet do not have pages (Paling, 2015).

Edit-a-thons to add or correct information have drawn attention to gendered knowledge gaps (BBC, 2016; Koh, 2013; Smith, 2013; Yong, 2012). These interventions, particularly among scholars, strongly suggest increasing concern over Wikipedia's content fairness and viability. Despite these biases, Wikipedia is perhaps the most flexible, accessible, and distributable platform for knowledge in the Web 2.0 era and might be "the last encyclopedia" (Kill, 2012, in video). It is the fifth highest ranked website globally for daily visitors (Alexa, 2017). Moreover, journalists and judges rely on it. Between 2004 and 2007 more than 100 U.S. judicial rulings accessed it (Cohen, 2007) and by 2009 over 400 U.S. judicial opinions referred to Wikipedia (Peoples, 2009), a trend that continues (Volokh, 2017). Journalists at major newspapers increasingly use Wikipedia for information about business, the arts, politics, cultural trends, and other topics, often positively framing Wikipedia as a source (Messner \& South, 2011). Wikipedia has thus become a major source of reference for news media reporting and judicial processes.

Women's and girls' voices and knowledges need to be part of this important online information space in order to make its content fair, comprehensive and dynamic for all users and to promote the democratic potential of the internet (Eckert \& Steiner, 2013). As one study found, content is connected to identity, as only women wrote about feminisms (Eckert \& Steiner, 2013). The lack of women contributors "has arguably skewed the information found on the site, resulting in a men-dominated knowledge base in some parts of Wikipedia" (Collier \& Bear, 2012, p. 2).

The gender gap on Wikipedia matters, mirroring similar gaps found in science, technology, engineering, and math (STEM). These gaps originate in the socio-cultural construction of the computer-oriented "geek" or "hacker" space as unwelcome to women (Ford \& Wajcman, 2017; Google Computer Science Report, 2014; No Ceilings Organization, 2015). Several related reasons for women's lower levels of participation are lack of self-confidence (Gardner, 2011; White \& Massiha, 2016), women's culturally encouraged resistance to regarding themselves as experts, and a lower self-perception of their online skills (Hargittai \& Shafer, 2006). Focusing on Wikipedia specifically, the Eckert and Steiner (2013) found both men and women reported a perceived lack of time and expertise as reasons for not contributing content to Wikipedia, but negative interactions and/or concerns over unpleasant experiences alienated women particularly. Online abuse, which targets women in higher frequency than men - and with a different quality including sexual harassment and rape threats - has become a major problem (Eckert, 2018) and another barrier to participation for some women. 
The gender gap and related scholarship prompted us to design an intervention called Wikid Grrls to teach teenage girls online skills for knowledge projects. Scholarship suggests that girls develop perceptions of their role in computing early on, ultimately revealing trends that computers are not for girls. The implications include trouble catching up or becoming involved in computer later in life, if they choose careers in computer-related fields (Code, 2016; Google, 2014; Kast, 2015; Margolis \& Fisher, 2002). In developing Wikid Grrls, we identified a similar program developed by Puchner, Markowitz, and Hedley (2015) that found interventions focused on gender and race in technology improved students' awareness of existing gaps and limitations of online spaces. Hence, we launched Wikid Grrls in Maryland in $2013^{1}$ as a free after-school workshop for middle school girls with ten sessions, one hour per week, throughout the school semester. In 2015, we implemented the program in Detroit Public Schools. This study details the results of the program and its potential as a feminist intervention.

\section{FEMINIST INTERVENTION THEORIES AND READER-TO-LEADER FRAMEWORK}

Since the advent of the internet, feminist scholars have studied the meaning of online spaces for feminisms. Over the past fifteen years they especially focused on teasing out what challenges women and minorities face in the digital, networked era. Challenges include: establishing access, literacy, and resources (Fotopoulou, 2014; Hargittai \& Shaw, 2015; Wajcman, 2008); handling sexism, misogyny and online abuse which have dramatically increased over the past few years (BanetWeiser \& Miltner, 2016; Citron \& Franks, 2014; Duggan, 2014; Jane, 2014; Mantilla 2013; Paling 2015) and curbing digital industries that struggle with gender gaps and discrimination (Vassallo et al., 2016).

Feminist intervention scholarship and the reader-to-leader framework (Preece \& Schneiderman, 2009) provided the theoretical underpinning for our study. Situated at the core of feminist scholarship are interventions (Fonow \& Cook, 1991), a principle that remains salient for digital realms as seen in projects such as Girls Who Code and Black Girls Code. Wikid Grrls was designed to teach girls online skills for their own use and improvement and to enhance the potential of girls' future participation in online content production, especially for knowledge sites such as Wikipedia.

The reader-to-leader framework is well suited for involving girls in knowledge-based projects (Preece \& Shneiderman, 2009). Readers start with reading, actively browsing and searching sites repeatedly. They are curious to find answers and are equipped with information-finding skills. Repeated engagement with a site may lead to rating, tagging, reviewing, posting and uploading content. Gradually, contributors develop a sense of belonging and move to collaboration, developing relationships to work on larger projects. Only a few users emerge as

\footnotetext{
${ }^{1}$ This included team members other than the current team; one author of this study led both teams in Maryland and Detroit.
} 
leaders, encouraging others to participate, helping them to get started, and mediating conflicts.

\section{LITERATURE REVIEW}

The ability to evaluate information online for accuracy and credibility is an essential component in participating in knowledge projects like Wikipedia. However, the results of one study, which analyzed 7,804 responses of middle school to undergraduate students, found an absence of critical reasoning applied to source materials; essentially, students had difficulty in delineating the difference between credible information sources and egregiously bias information sources (Wineburg \& McGrew, 2016). Interventions and research initiatives designed to improve critical thinking, tech skills, and media literacy skills have been deployed by universities and by NGOs such as Black Girls Code and Girls Who Code. Programs sometimes focus on higher education (Crandall, 2016; Fleming, 2016), high school (Greene et al., 2015), and/or with middle school students (Puchner, Markowitz, \& Hedley, 2015) as the target audience for their curriculum. Sometimes programs focus on teachers and administration (Mahoney \& Khwaja, 2016; Schmidt, 2013). Literature on K-12 programs typically distinguishes between out-of school time programs (OST), including after school-programs, and those programs that are part of the regular school day. Designed as an after school-program, Wikid Grrls aligns within the parameters of an OST, making OST studies the most relevant for review. OST programs designed to teach skills in science, technology, engineering and math are an appropriate benchmark for our workshop, which introduces girls to elements of coding and the internet's infrastructure.

The most comprehensive study of STEM OST programs in the U.S. included more than forty interviews with science program leaders and a survey of 417 programs (Laursen, Thiry, Archie, \& Crane, 2013). The authors found that more than half of OSTs were hosted by universities $(26 \%)$ or non-governmental organizations (25\%), followed by museums/science centers (15\%) and K-12 schools (12\%). OST programs hosted by K-12 schools only featured $40.2 \%$ girls and were the least ethnically diverse participant pool among all organization types. University programs featured a much higher proportion of Blacks and Latina/os. Laursen et al. (2013) concluded, "policy and programming efforts to encourage girls in science are finally bearing fruit" (p. 46), albeit still lacking inclusion of participants with disabilities. A high enrolment of minorities depends on actively building a diverse participant pool (Thiry, Archie, Arreola-Pena, \& Laursen, 2015).

Positive experiences for girls in such programs were rooted in likeable, engaged and enthusiastic instructors, collaboration, engaging and relevant curricula, exploring STEM in depth and long-term, inspiring career exploration, and using role models and field trips (Mosatche, Matloff-Nieves, Kekelis, \& Lawner, 2013). Other studies focusing on specific programs demonstrated benefits for girls. For instance, Koch, Gorges, and Penuel (2012) found in a summer school program teaching math to more than 2,000 girls in the U.S. and Canada that after the program their IT literacy improved, and they perceived IT careers not only possible 
but "collaborative, fun, and intellectually stimulating" (p. 60). Another program on using power monitoring devices with 246 middle school students, with gender parity, from six schools in four U.S. states showed aspirations for STEM careers for girls started lower than for boys before the program but advanced toward the level of the boys afterwards (Knezek, Christensen, Tyler-Wood, \& Periathiruvadi, 2013).

Other programs showed more mixed results for long-term attitudes. For instance, a summer program to educate girls on information technology at a U.S. Midwestern university demonstrated that girls enjoyed the two-day camp, yet their interest in future STEM careers was not retained (Outlay, Platt, \& Conroy, 2014). Marcu et al. (2010) found in an eight-week after-school program on engineering for minority low-income middle school girls that most participants expressed heightened confidence and understanding of STEM related fields but the number of girls desiring a career in STEM did not increase because of the program. Weisgram and Bigler (2007) concluded that only girls who learned about gender discrimination showed "increases in science self-efficacy and belief in the value of science" (p. 262). Further, most OST programs used summer time or a block of several days whereas our Wikid Grrls program was designed to accompany students throughout a regular semester. Donner and Wang (2013) emphasized successful programs need consistent training, not just a class here or there. Clearly, previous studies demonstrated the emancipatory potential that media literacy initiatives have brought to overcome gender inequity in STEM. Similarly, we see this potential being realized also toward alleviating inequities for Wikipedia if media literacy initiatives are deployed to address its persistent gender gap.

While not a classroom intervention designed to teach STEM skills directly, one of the goals of Wikid Grrls was to challenge girls' perceptions of opportunities in STEM fields. In practical terms, our workshop was organized somewhat differently from those mentioned above. We designed Wikid Grrls to accompany girls during a semester, in ten weekly one-hour after-school sessions at their school, thus avoiding transportation issues. Wikid Grrls targeted primarily public schools while being operated by a small university-based team. Financed by grants, the program was offered free-of-charge to the schools and participants. Skills taught in the workshop included wiki article creation, evaluating sources, proper citation, copyright and creative commons; collaboration, internet safety and netiquette; search techniques; data-mining tools such as Google Trends, building online surveys, use of innovative presentation software (Prezi), and using basic HTML to embed content into articles.

\section{METHOD}

To assess the impact of our workshop pilot in Maryland in 2013, we used a pre- and post-workshop survey, as commonly employed in similar programs. Questionnaires included closed questions (yes/no; Likert-scale) on skills such as searching online, conducting online surveys, knowledge about wikis and selfassessment of confidence, demographic questions on age, race/ethnicity and computer and internet use, and open-ended questions for feedback on the workshop. 
In the pilot, five grant-paid graduate and undergraduate students taught forty-three girls in four schools (three public; one private ${ }^{2}$ ). Participants' age ranged from eleven- to fifteen years- old; two thirds were eleven or twelve years old; $32 \%$ identified as Caucasian, $27 \%$ as Black, $22 \%$ as Latina, $10 \%$ as Asian, $5 \%$ as African and $3 \%$ as American Indian/Alaskan Native. Of the forty-three, thirty-seven completed the pre-workshop and twenty-five the post-workshop survey. As typed responses were brief and often not specific (e.g. only writing "doing projects"), we included pre- and post-workshop interviews for the iterations in Detroit for a more complete understanding of the participants' experiences. The survey was also adjusted to capture demographics and computer/internet use prior to the workshop.

In Detroit, during the 2015-2016 school year, seven undergraduate honors students ${ }^{3}$ taught the workshops, receiving credits towards a service-learning requirement. Of twelve public schools initially contacted, three hosted the workshop and thirty-seven girls participated; thirty-seven completed a preworkshop survey and thirty-two a pre-workshop interviews; nineteen girls participated in post-workshop interviews and thirteen in a post-workshop survey. ${ }^{4}$ At one school, the number of participants decreased during the semester due to a competing sports team. Participants' age ranged from eleven- to fourteen- yearsold. More than half of the girls identified as Black, more than one third as Asian, $16 \%$ as Caucasian, $11 \%$ as other and $5 \%$ as American Indian. Interviews were transcribed by a graduate student and analyzed by three researchers individually and inductively with manual open coding for emerging themes. Researchers then compared individual analysis for reliability and validity to solidify themes and supporting material.

Participants in Maryland and Detroit self-reported they started using a computer regularly on average by age seven, with an age range from three to twelve. Students equally reported using the internet by the age of seven years, with a very similar age range from three to eleven years. Hence, most students conflated computer use and internet access. When asked to compare their use of computers and cell phones regarding internet access, the participants mixed up these devices as both can access the internet. Nearly all participants had internet access on a personal smartphone. While not all devices and computers have internet access, home computer access among children is closely followed by home internet use

\footnotetext{
${ }^{2}$ The one private school was included as part of the seed grant conditions.

${ }^{3}$ Several Wikid Grrls team members were minorities, with Latino, Asian, Jewish, LGBTQ, and/or immigrant backgrounds. Two members were men.

${ }^{4}$ In our analysis for the Detroit participants we focus on the interviews.
} 
(Child Trends, 2015), albeit both differ according to race/ethnicity: among Asian children $91 \%$ had home computer and $62 \%$ home internet access; followed by whites with 87 and $64 \%$ respectively. Hispanics and Blacks had very similar percentages with $65 / 66 \%$ respectively for home computer access and $48 / 47 \%$ respectively for home internet access. Most of our participants reported sharing a laptop with family members, work on slow or broken machines, or only access a laptop at school. This is noteworthy as a summary of recent studies found that students with exclusive access to learning technology achieve the highest benefit (Darling-Hammond, Zielezinski, \& Goldman, 2014).

\section{FINDINGS FROM THE MARYLAND PILOT STUDY}

Before the workshop, when asked about the websites they most often visit, participants named a search engine, social media portals, and educational sites for completing homework. Several noted they already used Wikipedia before the workshop. Regular and occasional usage of Wikipedia increased slightly after the workshop. Similarly, slightly more participants reported knowing how to find information online after the workshop. The percentage of participants who understood what a wiki is increased more than threefold as a result of the workshop (Figure 1). More students reported that they knew how to create an online survey after the workshop.

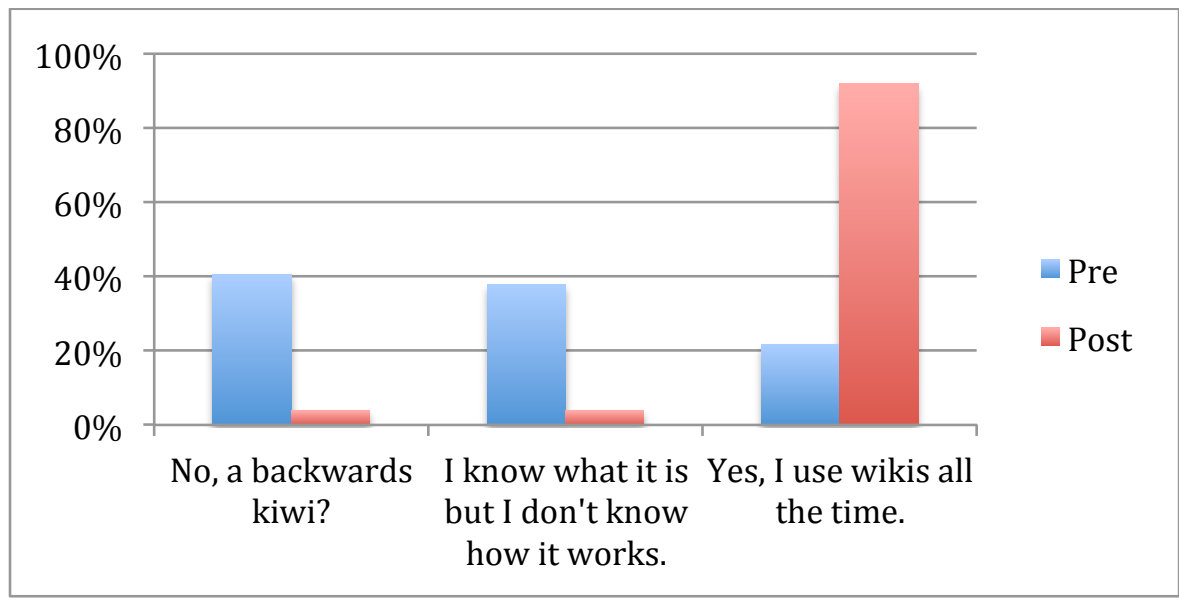

\section{Figure 1}

Do you know what a wiki is?

Pre and post workshop responses in percent (Pre: $N=37$, Post: $N=25$ )

Perhaps most interestingly, after the workshop concluded, almost three quarters reported that they would like to share their knowledge with others (Figure 2). Similarly, more than $40 \%$ assessed that their interest in sharing knowledge had grown compared to before the workshop. 


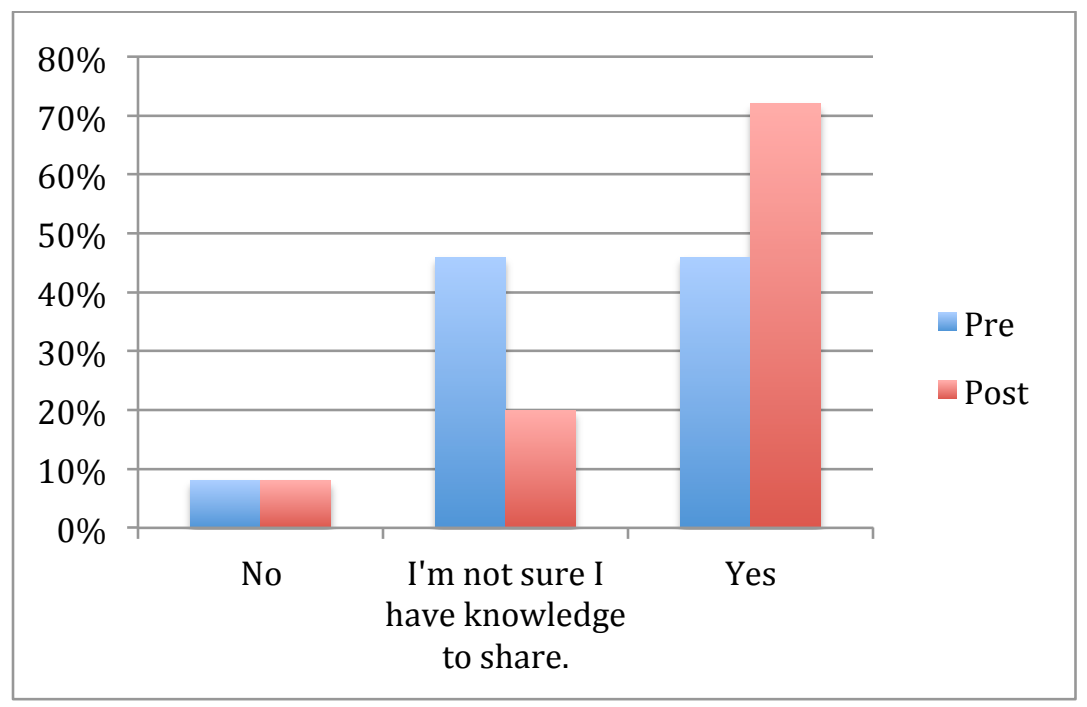

\section{Figure 2}

Would you like to be able to share your knowledge with others?

Pre and post workshop responses in percent (Pre: $N=37$, Post: $N=25$ )

Following the workshop, more participants used the internet to find practical information. Hence, specific skills such as creating online surveys, using a wiki, and finding information online increased as well as participants' confidence in sharing knowledge and using the internet after the workshop. Previous studies on interventions in STEM similarly showed short-term increases in awareness, confidence, and skills.

Open-ended questions on what they liked, or not, about Wikid Grrls indicated participants' overall satisfaction. A typical answer was: "I like how I can look on different pages that are on topics like pediatricians, doctors and I also get to make my own wiki to help other people know about my subject, too." Other favorite elements included snacks, working on the website Codecademy (for basic coding), collaborating, and individual attention paid to participants. In contrast, creating online surveys and critiquing each other's work did not appeal to participants. Some students did not enjoy the writing portion of the program. Students suggested doing more wikis, having more time, a field trip, and learning about Google docs among other ideas. Many participants used the workshop as a means of catching up on basic online skills to function as digital citizens in the $21^{\text {st }}$ century but that their school was unable to teach efficiently. 


\section{FINDINGS FROM DETROIT PUBLIC SCHOOLS}

Adding pre- and post-workshop interviews with participants for the two iterations of the workshop in Detroit Public Schools provided us with more in-depth insights into how girls make sense of their relationship with online spaces and agency regarding technology, and how their views changed during the workshop. We conducted interviews with participating girls before and after the first and last Wikid Grrls session, audio-recorded and transcribed their answers and used textual analysis to develop the themes arising from their answers.

\section{Computer Skills Improved Despite Varying Levels of Initial Proficiency}

Sophistication regarding computer skills ranged widely in the pre-workshop interviews. Participants often described their skills as "basic" or "average" and named "typing" or "searching" as skills. One girl said she could upload and download information, another said she could evaluate information online, and only one student reported attending a previous coding class.

Although internet access is largely ubiquitous, frequently access is provided only through a smartphone, which does not lend itself as easily to knowledge projects (Lih, 2015). The lack of a personal computer may have contributed to the lack of specificity when participants were asked to assess computer skill level. Computer skills, such as coding, uploading, and article writing are best facilitated through a desktop or laptop computer. For instance, college students report laptops are better than smartphones for learning, completing homework and group work (Pearson, 2015). Yet, almost all teenagers from higher-income families had a laptop at home (92 percent) compared to only roughly half of the teenagers in lowerincome families (54 percent) (Common Sense Census, 2015).

The generalization of "computer skills" may indicate other problems. The overall lack of sophistication regarding computer skills may seem counter intuitive given the ages of the girls. As so-called digital natives it is often assumed they already possess innate knowledge about technology (Hargittai, 2010). But immersion does not necessarily translate into technical skill or knowledges.

A majority of the participants who completed Wikid Grrls noted improvements in their computer skills and were better equipped to talk about technology including: improved laptop/computer keyboard skills (as opposed to smart phone keyboards, learning short cuts such as for switching screens and copy and paste), internet safety, presentation technology, coding, search strategies and writing. Some recalled specific skills and could describe those skills using descriptive language. Other students could recall the name for the skill but could not recall specifics. These skills developed the potential of students to produce or reproduce online information instead of solely consuming online information, which was a major theme in the pre-workshop interviews. Students reported using the skills acquired from the workshop in their classes. 


\section{Perceptions of Wikipedia}

Three broad themes emerged around Wikipedia. Before the workshop, some participants perceived Wikipedia as either entirely erroneous and not to be trusted, while others judged it static and/or an authority that mostly presents trustworthy information. These perceptions were heavily influenced by teachers, parents, and administration. Our findings are consistent with Mahoney and Khwaja (2016) as we also conclude that teachers often act as a type of gatekeeper for students' views on technology.

Wikipedia as Erroneous. In pre-workshop interviews in Detroit, several participants did not consider Wikipedia as a trustworthy source of information. One girl said: "Usually people say it has false information. So, I tend to stay away from it." (S.K. Detroit, Pre-Workshop Interview, 2015). Another one stated: "I don't really use Wikipedia because somebody told me that the stuff on there is not true" (J.J., Detroit, Pre-Workshop Interview, 2016). Participants explained that teachers would not let them use Wikipedia as a source for research projects. For these students, Wikipedia as a source of knowledge was dubious as authority figures like a teacher or parent cautioned them against fully trusting information stemming from Wikipedia.

Wikipedia as Static Source for Knowledge. Despite some students explaining that various past teachers had discouraged them from using Wikipedia altogether, pre-workshop interviews demonstrated most students perceived Wikipedia as a useful source for homework to find information on (historical) figures, events or celebrities such as Whitney Houston, Bill Cosby, Jaime Foxx, Martin Luther King Jr., Barack Obama, and Percy Julian. For them, Wikipedia was a site containing static knowledge about facts, figures, or trivia. Students may view knowledge in this manner given what they are asked to recall for tests or projects they are researching. Projects seem to reduce historical figures or celebrities to a series of facts feeding into what bell hooks (1994) and Paolo Freire (2000) call a "banking system" of storing and retrieving knowledge rather than dynamic learning applied in daily life.

Wikipedia as Authority. Other participants regarded Wikipedia as a somewhat reliable source of information, saying its content is generally trustworthy since editors oversee changes. If a change is incorrect, they suggested, someone will notice and correct it. One student said:

what people edit... they don't edit stupid things...so if they're reading the article and something is stupid they'll erase it. So I think everything on Wikipedia, is not always true, but it's basically kind of true. (D.H., Detroit, Post-Workshop Interview, 2016).

Other contributors, whom participants saw as having more knowledge than them, were considered final authorities on Wikipedia. When asked how she would describe Wikipedia to a friend, one participant said it is "like putting something on the internet and then somebody else fixing or editing it" (J.R., Detroit, PostWorkshop Interview, 2016). When Wikid Grrls instructors talked about the impetus 
of the program being Wikipedia's gender gap some participants seemed surprised by the information; for many the implication that gender could impact the nature of knowledge conveyed via technology (Wajcman, 2008) was new.

\section{Critical Responses to Wikipedia Before the Workshop}

Pre-intervention, few students were aware of the need to exercise source criticism when using Wikipedia. For most, Wikipedia was either a useful authority or discouraged by other authorities (teachers/parents). A rare exception was a girl who said before the workshop: "if you look up Google out there, and the same question on Wikipedia, you'll get two different answers" (S.S., Detroit, PreWorkshop Interview, 2016). Post-workshop, the ability to exercise critical thinking toward information had increased among participants. They reported a heightened awareness of Wikipedia's strengths and weaknesses regarding content accuracy. They had learned that content has to be verified rather than taken at face value. One student said:

We learned to use these skills that we could use to know if it's right, you know, back it up with other sources and stuff like that. So I would tell them you can use Wikipedia but you have to check other sources. Wikipedia's not bad you just have to think a little harder basically. (J.J., Detroit, PostWorkshop Interview, 2016)

For another student who completed the workshop, the authority of the people who edit Wikipedia shifted from being experts to recognizing them as "regular people:"

I always wondered about how they put the information up on there. ...it's like regular people who had information they want to share so they will go to this edit section or, like, review. (C.O., Detroit, Post-Workshop Interview, 2015)

Participants learned to qualify the information potential of Wikipedia and recognized that not all knowledge is equal or accurate, and "facts" are malleable. For example, one student explained the benefits of Wikipedia this way: "It wasn't as controlling as other sites can be. You were able to edit what you want and create" (B.S., Detroit, Post-Workshop Interview, 2015). When asked what was problematic about Wikipedia, she added: "You can edit pretty much anything even if it's not true or even good," understanding information can be biased by editors.

While not every participant demonstrated increased awareness of gender gaps on Wikipedia, many of them did, consistent with other scholarship (Puchner, Markowitz, \& Hedley, 2015). They learned to examine sources more thoroughly for information and to question the production and consumption of knowledge. Hence, they understood through practical learning the tenet of digital feminist theory that technology and identity are mutually constructed and constitute each other (Wacjman, 2008), that these concepts are fluent, human-made and not fixed or stable. Furthermore, they realized their own potential to challenge the presented 
knowledge and to use their own education to practice their freedom of expression (hooks, 1994).

\section{Contributing to Wikipedia}

All Wikid Grrls participants were asked to create an article on a safe, private wiki site hosted by the free service Wiki Spaces. Initially, the article project helped girls to apply skills that would be required to edit a Wikipedia article. For some, their article remained a rough page with few hyperlinks and little detail. Other students fleshed out their articles, helped fellow participants by editing or commenting, and some started several articles.

After the workshop, we asked students if they would consider contributing to Wikipedia. Although most participants were imaginative and ambitious when talking about the creative potentials of the internet in general and Wikipedia specifically, they stumbled when asked to describe concrete examples of what they would like to contribute, if given the chance. In post-workshop interviews, many participants answered "yes" to the question whether they could see themselves contributing an article to Wikipedia, but had only vague answers about what specifically they might want to write about. Typical answers included "maybe environment, I don't know" and "something about history or something like that "cause I like history" and "I read a lot books so I know a lot about different authors and books you know so I could share my knowledge on that." Nevertheless, students took their choices for contributions seriously as they had learned how much work it takes to write knowledge articles. One student explained her vagueness as follows: "I'd probably edit something that I was interested in, like something I felt passionate about. I wouldn't just go and edit anything because I probably don't have knowledge on it" (J.J., Detroit, Post-Workshop Interview, 2016). Another one was concerned about backlash to her potential contribution and said: "Well, I won't edit nothing ...'cuz sometime people say things that are offensive" (A.A., Detroit, Post-Workshop Interview, 2016). Given these were mostly middle school girls who are still grappling with many issues regarding their future (careers), their enthusiasm to contribute appears more important than the exact content.

When interviewers asked for clarification about what students would edit on Wikipedia, many cited favored celebrities, musicians, or television series. In fact, when deciding what to write about in their practice wikis, topics typically fell into two categories: entertainment or community. For one girl, this meant writing about her school's cheerleading team, while another wrote a wiki with advice on how to transition from middle to high school. Issues facing the racial communities of participants also emerged as potential topics, as one participant said she wanted to write about "people getting killed by cops."

Many of the Wikid Grrls participants developed a potential to edit Wikipedia articles. Their technical skill level with coding and hot key use increased enough to accomplish such a task. Their potential content contributions were focused on critically engaging with popular culture or community issues, reflecting their real and imaginative worlds. 


\section{Making Sense of Wikipedia and Knowledge After the Workshop}

Students struggled with the concept of knowledge as opinion versus knowledge as authoritative. For some students, knowledge was conflated with opinion and their idea of sharing knowledge online was to share their opinion. Others believed knowledge was fact dictated by an authority such as an editor. Students generally said they believed knowledge needed to be true and verified, since false information would potentially harm others. Yet, some participants began to distrust Wikipedia altogether. One student described the reason for her distrust this way:

Sometimes [Wikipedia] is kinda bad because it's like looking up a famous person for like a report and they go on Wikipedia and they write that down and they get it wrong because somebody edited it. (J.R., Detroit, PostWorkshop Interview,

2016).

Students' perceptions of Wikipedia were also influenced by previous experiences with other internet platforms. After the workshop one student compared Wikipedia to social media which everyone can access:

I would describe to one of my friends [that] it's like a big social media account where everyone's part of it. You can create stuff and edit things, join together and learn new things and everyone can have an influence. (B.S., Detroit, Post-Workshop Interview, 2016).

Another student said: "[Wikipedia] is like another form of Google, but it can give you more information" (J.R., Detroit, Post-Workshop Interview, 2016). Seen through the lens of other familiar online spaces, they understood knowledges are produced, developed, shared, and contextualized within a community (Longino, 2010). By recognizing Wikipedia as a social media site, the students acknowledged how knowledge is malleable, never wholly complete until everyone participates. Wikipedia has been extensively studied as a source of objective knowledge and found to be reliable on the whole. As Haslam (2017) concluded, after summarizing numerous studies of Wikipedia's accuracy, "a Wikipedia article should be critically evaluated as one information source among many: not pre-emptively dismissed as lacking value" (p. 248). Similarly, a Nature study determined that Wikipedia content is thoroughly on par with that of Encyclopedia Britannica (Giles, 2005) in terms of overall accuracy (albeit this does not negate biases this encyclopedia may contain). What we asked of participants, therefore, was not to shun Wikipedia content as untrustworthy nor idolize it as the ultimate truth, but to exercise source criticism, i.e. analyzing the credibility and reliability of each page based on factors such as the citations used, the number of page edits, the source domain names etc. When theoretically explained, the impact of gender on knowledge and technology use (Wajcman, 2008) was abstract and surprising for participants. But through the workshop they learned to understand this relationship in their own creation of and 
interaction with wikis. This demonstrated how important it is to combine theory with practice in teaching, confirming feminist approaches to pedagogy that emphasize that classroom learning needs to be relevant to life experiences (hooks, 1994).

Viewing knowledge as a social endeavor brought problematic challenges and participants developed critical thinking through the pedagogy of theory and practice (hooks, 1994). Stereotypes about girls meant the students undervalued their own and other girls' knowledge. One student suggested girls were untrustworthy: "Well, I think, it's not a problem girls being online. But, girls, sometimes take lies and post them as if they're real." Another student expressed concerned about editing because it might hurt the original writer's feelings but also recognized that collaboration improves information: "If you are editing it, then you are helping them ... you add extra information that you had, that they didn't have. I feel like it's okay if you edit somebodies stuff." In this way, the harmony among group members took precedence over having the most accurate information, reflecting the way girls are socialized to strive for unity.

\section{DISCUSSION}

It is clear from our initial pilot run of the program in Maryland and the results of subsequent iterations that programs such as Wikid Grrls have beneficial effects on girls' self-confidence, critical thinking abilities, and awareness of the internet's knowledge creating and sharing capabilities. However, survey results demonstrated that learning gains may be temporary, leaving an insufficient mark on the girls' actual participation in knowledge sites such as Wikipedia. Therefore, it is crucial that media literacy programs on online skills, like this one, be integrated into the school curriculum, rather than offered as a one-time workshop or summer program only.

\section{Feminist Intervention in Action}

Our workshop for middle-school girls was informed by the feminist principles of using situations-at-hand and conducting action-oriented research as well as the approach of intersectionality. We argue that women and girls should be the focus of practical interventions which attempt to reduce disparity between people. To do so, we needed to work with already established spaces and systems. We established partnerships with schools and conducted a workshop developing online knowledge creation skills that was open only to girls. In that way, by providing girls with their own space in which to familiarize themselves with the Wikipedia environment, we disrupted the traditional co-educational school organization of STEM teaching, following many other successful examples such as Girls Who Code or Black Girls Code. Such action is not aimed at privileging girls, but rather compensating for the cultural dominance of boys in the realm of computing, encouraged since the mid-1980s by the computer game industry, aimed overwhelmingly at satisfying boys' needs for entertainment and leaving girls behind (Margolis \& Fisher, 2002). The disruptive nature of our intervention allowed us to 
establish a new form of front row access for girls who sometimes feel like they can only take the "back seat" at the computer, when boys are present.

Our curriculum included a session about online safety, which is a critical component of feminist research about the internet, and in an early iteration of the workshop, participants completed the "Take This Lollipop" interactive exercise online, later discussing what they learned. This experience revealed how much information they are giving away on Facebook and how it can be used in possibly harmful ways (Zada, 2011). Such knowledge and preparedness could not be more relevant in the age of Cambridge Analytica and other infamous data breaches affecting social networks (Osborne, 2018). Finally, our intervention focused specifically on Wikipedia both as a format of content creation and as an existing, crucially important web platform that continues to struggle with equitable gender representation. One of the barriers to entry in editing Wikipedia is the specific style and etiquette of editing or adding an article. By offering participants a safe, miniaturized version of Wikipedia on their own Wikispace site, we allowed them to be familiar with the conventions of editing and collaborating on the real Wikipedia platform.

We combined this feminist approach with a step-by-step framework to turn girls from readers of Wikipedia into creators of content, becoming leaders on the "back side" of shaping online spaces. Applying the reader-to-leader framework described by Preece and Shneiderman (2009) worked well for Wikid Grrls. In the next section, we detail how we implemented their approach in our after-school program.

\section{Applied Reader-to-Leader Framework}

For attracting users to the first level of participation, namely becoming readers, Preece and Shneiderman (2009) detailed multiple usability and sociability factors, including encouragement from trusted people. This, we argue can include (after-) school teachers, who guide girls to read articles on Wikipedia about their school, last names and role models. Wikipedia offers a Simple English version tailored to students and children, making it easier for younger students to get familiar with the online encyclopedia.

Repeated engagement with a site may lead to activities such as rating, tagging, reviewing, posting and uploading content. Within the Wikid Grrls project, we used Wiki Spaces as a free and safe platform for girls to write their own content after reading Wikipedia articles. We set up the system for them and walked them through the first steps of creating an article for a low-threshold entry into content creation while maintaining a high-level safety and privacy.

The third phase that Preece and Shneiderman described is collaboration, defined by developing relationships with others to work together. In Wikid Grrls, we guided participants in commenting on each other's articles, discussing civility online and the importance of respectful interaction when giving feedback, as well as leaving identifiable traces after making an edit. This increased respect for each other and their work. We encouraged the girls to collaborate in determining features on the wiki. Frequently, desk neighbors collaborated to complete a task. 
As Preece and Shneiderman described, only a few contributors emerge as leaders, encouraging others to participate, helping them get started, and mediating conflicts. Within Wikid Grrls, we saw beginnings of this. For example, two girls who were passionate after participating in the first workshop enrolled for a second semester, bringing their acquired skills into the class to lead their peers. Without prompting, these girls promoted Wikid Grrls among peers and authored testimonials to increase recruitment for subsequent semesters.

Wikid Grrls also had an additional impact on the undergraduate students who served as student-teachers for the workshop. Two of the student-teachers in Detroit took on an additional leadership role by advocating for the service learning opportunity among their peers in the honors college. They created additional materials for participants, repeatedly suggested ideas for the program, and several participated in a conference workshop to show how Wikid Grrls works from the student-teachers' perspective. Together, these results suggest Wikid Grrls can successfully move students at all levels of education from users of information to collaborators, producers, teachers, and leaders.

\section{CONCLUSION}

\section{Online Skills for Girls in a Complex Web of Opportunities}

Interventions to teach girls online skills are successful, as previous studies and this study demonstrated. Such workshops do increase specific skills and confidence in them at the time of learning and heighten awareness of the availability of STEM careers to girls. In this sense, Wikid Grrls was effective as a feminist intervention, bringing concrete knowledges to girls who used it and in turn taught others. Yet, several studies suggested that the connections between such interventions and girls actually pursuing STEM careers are weak (Marcu et al. 2010; Outlay, Platt, \& Conroy, 2014). Future studies would benefit from a longitudinal design in order to further analyze the quantity and quality of connections.

Additionally, several studies indicated the need for teachers of computer and internet after-school programs to be trained in advance, as many lack necessary knowledge in computing skills themselves (Donner \& Wang, 2013; Google, 2014; Koch, Gorges, \& Penuel, 2012). Wikid Grrls instructors, largely undergraduate students, experienced a similar obstacle. However, recruiting teachers from the schools has not appeared feasible. Generally, K-12 educators are less likely to focus on programs regarding media literacy and technology skills than their college or university counterparts, particularly if they feel that they lacked training or personal experience (Schmidt, 2013). Beyond training as an obstacle, for Wikid Grrls in Detroit, public school teachers protested their overburdened and frustrating working conditions (Higgins, 2016). Involving schoolteachers may become more feasible if they are supported through training and incentives, such as compensation for participation in STEM/computer training.

\section{Implications for future research}


While previous studies, including large-scale comparative reviews (Laursen et al., 2013), showed that STEM-focused after-school programs vary greatly in their approaches, they also indicated that a high number of such programs have developed over the past twenty years. This trend points to the necessity of including computer and online skills in the regular school curriculum, rather than as a separate event coordinated by volunteers, researchers, NGOs and other (private) organizations. It seems apparent that more young people need to be equipped with relevant knowledge to be able to navigate the ubiquitous technology in daily life that is a pillar of our current digital era. Critical media literacy education is vital as Wineburg and McGrew's 2015-2016 nationwide survey also demonstrated that students, ranging from middle school to college age, are largely unable to tell news from fake stories or advertising, and generally display poor analysis of source credibility (2016).

Future research should investigate methods of integrating such workshops for girls into the regular public school curriculum at a minimal cost. Ample resources exist for this to become a reality. For instance, our program provides the 10 -week curriculum free of charge and may be requested via our website. Similarly, Wiki Education, started in 2013 by the Wikimedia Foundation, offers invaluable teaching resources for instructors seeking to use Wikipedia as a teaching tool ${ }^{5}$. These materials may be easily adapted for use with middle-schoolers, which research shows is the crucial moment for girls in deciding whether or not to pursue careers in computer science and STEM. Most importantly, it is crucial to continue piloting after-school programs for girls that would lead to long-term results. To that end, a grounding in theory and a knowledge of existing programs is essential. In our case, we used feminist intervention and the reader-to-leader framework. Concurrently, it is prudent to adapt media literacy projects to particularly disadvantaged groups. Doing so provides minority students with opportunities to not only have access to new tools, but also to aid them in innovating with and within these technologies (Scott, Sheridan, \& Clark, 2015). For example, the authors' culturally responsive computing programs improved STEM learning for African-American and Latina girls. Dominant cultures convey ideological value systems that implicitly suggest minorities and women are not part of technology or scientific achievements, yet this assumption is an erasure of their histories. Emphasizing the contributions of women and minorities to technological developments and innovative scientific concepts has the potential to connect minority girl students' cultural histories to possible future contributions to STEM fields. When technology is introduced as culturally constructed, most often by dominant groups, minority girls learn that technology can be used toward building social justice by re-including women and minorities as producers and designers and recognizing them as such. This appears to be a promising approach to increase media literacy especially for minority girls.

Media literacy programs like ours and the (at least) 418 STEM-focused after school programs throughout the U.S., have a role in addressing the dearth of women in technology, and the overall lack of courses for online skills and computer science in U.S. schools. A 2014 national survey found that only $25 \%$ of U.S. schools

\footnotetext{
${ }^{5}$ Available at: https://wikiedu.org/for-instructors/
} 
offered computer-programming courses and, among those schools offering computer science, only 21\% offered AP classes (Google, 2014). The study concluded that the main reason for the dearth of computer science classes are requirements for schools to offer courses tied to testing as well as a lack of trained teachers.

In contrast, European countries have added coding to school curricula (School Education Gateway, 2015; Xinhua, 2015). Apart from arguing for a more systematically equal and fair socialization of genders regarding technology literacy, teaching online computer skills can be a gateway for school-aged girls to become interested in STEM careers, which is important if the U.S. wants to be competitive in STEM globally (Google, 2014; Microsoft, n.d.). In combination with solving other issues that make studying and working for women in technology fields still unpalatable (Kast, 2015), naturalizing the development of technology skills and confidence in them among girls early on is crucial. This will help shift the societal construction of technology and gender, which constitute each other in specific historic moments (Wajcman, 2008).

Intervening early is a first step that cannot be missed in an environment with barriers for girls and women in STEM at all educational and career levels from K12 , to college, to first and following jobs. Yet, interventions remain sparse, even if worthwhile and effective. Media literacy programs such as Wikid Grrls contribute to cultivating equity in information societies and help to level the playing field for all to participate to use media to innovate and to innovate the media themselves. Feminist theorizing on the malleable relationship between gender and technology (Wajcman, 2008; Margolis \& Fisher, 2002) and feminist pedagogy on theory and practice (hooks, 1994) need to work more understanding how short-term interventions translate into the possibilities of longitudinal impacts, and under which conditions they can be produced and nurtured. It appears that with rigid and limited school curricula, overburdened teachers, lack of discussions on technology influencing girls' self-perceptions of gender and technology, relatively brief interventions stoke hopes and inspire girls, but may not sustain these desires and fledgling skills in the long run. It remains a burden on girls to develop the grit to explore, enter and remain in men-dominated tech fields. Future studies need to examine the long-term trajectory of girls, especially of minorities, that successfully used media literacy project and skills to become effective and visible participants in the information age.

\section{REFERENCES}

Acker, J. K., \& Esseveld, J. (1991). Objectivity and truth: Problems in doing feminist research. In M. M. Fonow \& J. A. Cook (Eds.), IBeyond methodology: Feminist scholarship as lived research (pp. 133-153). Bloomington, IN: Indiana University Press.

Alexa. (2017, May 2). Top sites. Retrieved from http://www.alexa.com/topsites

Banet-Weiser, S., \& Miltner, K. M. (2016). \#MasculinitySoFragile: Culture, structure and networked misogyny. Feminist Media Studies, 16(1), 171-174. 
BBC. (2014). Wikipedia 'completely failed' to fix gender imbalance. Retrieved from http://www.bbc.com/news/business-28701772

BBC. (2016). Women take over Wikipedia. Retrieved from http://www.bbc.com/news/live/world-38243211

Child Trends. (2015). Home computer access and internet use. Retrieved from http://www.childtrends.org/wpcontent/uploads/2012/07/69_Computer_Use.pdf

Citron, D. K., \& Franks, M. A. (2014). Criminalizing revenge porn. Wake Forest Law Review, 49, 345.

Code. (2016). About Us. Retrieved from https://code.org/about

Cohen, N. (2007, January 29). Courts turn to Wikipedia, but selectively. New York Times. Retrieved from http://www.nytimes.com/2007/01/29/technology/29wikipedia.html

Cohen, N. (2011, January 12). Define gender gap? Look up Wikipedia's contributor list. New York Times. Retrieved from http://www.nytimes.com/2011/01/31/business/media/31link.html

Collier, B., \& Bear, J. (2012). Conflict, confidence, or criticism: An empirical examination of the gender gap in Wikipedia. Paper presented at the conference on Computer-Supported Cooperative Work, Seattle, WA. Retrieved from http://www.benccollier.com/

Common Sense Census. (2015). 2015 Media use by tweens and teens. Common Sense. Retrieved from https://www.commonsensemedia.org/research/thecommon-sense-census-media-use-by-tweens-and-teens

Crandall, H. (2016). Locating communication action outreach projects in the scholarship of media literacy pedagogy. Journal of media literacy education, 2(8), 110-121.

Darling-Hammond, L., Zielezinski, M. B., \& Goldman, S. (2014). Using technology to support at-risk students' learning. Retrieved Accessed from https://edpolicy.stanford.edu/sites/default/files/scope-pub-using-technologyreport.pdf

Donner, J., \& Wang, Y. (2013). Shifting expectations: Bringing STEM to scale through expanded learning systems." Afterschool Matters, 17, 50-57.

Duggan, M. (2014, October 22). Online harassment. Pew Research Center. Retrieved from http://www.pewinternet.org/2014/10/22/online-harassment/

Eckert, S. (2018). Fighting for recognition: Online abuse of women bloggers in Germany, Switzerland, the UK and US. New Media \& Society, 20(4), 12821302.

Eckert, S., \& Steiner, L. (2013). Wikipedia's Gender Gap. In Armstrong, C. (Ed.), Media Disparity: A Gender Battleground. (pp. 87-98). Lanham, MD: Lexington Books.

Fleming, J. (2016). What do fact have to do with it? Exploring instructional emphasis in the Stony Brook news literacy curriculum. Journal of Media Literacy Education, 7(3), 73-92.

Fonow, M. M., \& Cook, J. A. (1991). Back to the future: A look at the second wave of feminist epistemology and methodology. In M. M. Fonow \& J. A. Cook 
(Eds.), Beyond methodology. Feminist research scholarship as lived research, (pp. 1-15). Bloomington, IN: Indiana University Press.

Ford, H., \& Wajcman, J. (2017). 'Anyone can edit', not everyone does: Wikipedia and the gender gap. Social Studies of Science. DOI:

$10.1177 / 0306312717692172$

Fotopoulou, A. (2014). Digital and networked by default? Women's organizations and the social imaginary of networked feminism. New Media \& Society, 18(6), 989-1006.

Freire, P. (2000). Pedagogy of the oppressed. New York: Continuum.

Gardner, S. (2011, Feburary 19). Nine reasons women don't edit Wikipedia (in their own words) [web log comment]. Retrieved from

http://suegardner.org/2011/02/19/nine-reasons-why-women-dont-editwikipedia-in-their-own- words/

Giles, J. (2005). Special report: Internet encyclopedias go head to head. Nature, 438, 900-901.

Glott, R., Schmidt, P., \& Ghosh, R. (2010, March 15). Analysis of Wikipedia survey data. Age and gender differences. Retrieved from https://web.archive.org/web/20100414165445/http://wikipediasurvey.org/do cs/Wikipedia_Overview_15March2010-FINAL.pdf

Google Computer Science Report. (2014). Searching for computer science: access and barriers in U.S. K-12 education. Retrieved from https://services.google.com/fh/files/misc/searching-for-computerscience_report.pdf

Greene, K., Yanovitzky, I., Carpenter, A., Banerjee, S., Margsamen-Conrad, K., Hecht, M., \& Elek, E. (2015). A theory-grounded measure of adolescents' response to media literacy interventions. The Journal of Media Literacy Education, 7(2), 35-49.

Haraway, D. J. (1990). A cyborg manifesto: Science technology, and socialistfeminism in the late twentieth century." In D. J. Haraway (Ed.), Simians, cyborgs, and women: The reinvention of nature, (pp. 149-182). New York, NY: Routledge.

Hargittai, E., \& Shafer, S. (2006). Differences in actual and perceived online skills: The role of gender. Social Science Quarterly, 87(2), 432-448.

Hargittai, E., \& Shaw, A. (2015). Minding the skills gap. Information, Communication \& Society, 18(4), 424-442.

Haslam, T. (2017). Wikipedia and the humanities in higher education: Past time to renegotiate the relationship, International Journal of Information and Education Technology, 7(4), 246-251.

Higgins, L. (2016, January 11). DPS teachers at rally: Sick-outs a demand to be heard. Detroit Free Press. Retrieved from http://www.freep.com/story/news/local/michigan/detroit/2016/01/11/dpsschools-closed-sickouts/78618800/

hooks, b. (1994). Teaching to transgress. London: Routledge.

Jane, E. A. (2014). 'Back to the kitchen, cunt': Speaking the unspeakable about online misogyny. Continuum: Journal of Media \& Cultural Studies, 28(4), 
558-570.

Kast, R. (2015, June 8). 7 ways to recruit more women into tech careers. Wayne State University Commission on the Status of Women. Retrieved from http://blogs.wayne.edu/cosw/2015/06/08/7-ways-to-recruit-more-womeninto-tech-careers/

Kill, M. (2012, February 14). Knowledge and meaning in the information age. Maryland Institute for Technology in the Humanities. Retrieved from http://mith.umd.edu/dialogues/knowledge-and-meaning-in-the-informationage-a-humanist-perspective-on-wikipedia/

Koch, M., Gorges, T., \& Penuel, W. R. (2012). Build IT: Scaling and sustaining an afterschool computer science program for girls. Afterschool Matters, 16, 5866.

Koh, A. (2013, May 30). How to organize your own Wikipedia edit-a-thon. [web log comment] Chronicle of Higher Education. Retrieved from http://chronicle.com/blogs/profhacker/how-to-organize-your-ownwikipedia-edit-a-thon/49757

Knezek, G., Christensen, R., Tyler-Wood, T., \& Periathiruvadi, S. (2013). Impact of environmental power monitoring activities on middle school student perceptions of STEM. Science Education International, 24(1), 98-123.

Laursen, S., Thiry, H., Archie, T., \& Crane, R. (2013). Variations on a theme: Characteristics of out-of-school time science programs offered by distinct organization types. Afterschool Matters, 17, 36-49.

Lih, A. (2015, June 21). Can Wikipedia survive? New York Times. Retrieved from http://www.nytimes.com/2015/06/21/opinion/can-wikipediasurvive.html? $\mathrm{r}=0$

Longino, H. 2010. Feminist epistemology at Hypatia's 25th anniversary. Hypatia, 25(4), 733-741.

Mahoney, K., \& Khwaja, T. (2016). Living and leading in a digital age: A narrative study of the attitudes and perceptions of school leaders about media literacy. Journal of Media Literacy Education, 2(8), 77-98.

Mantilla, K. (2013). Gendertrolling: Misogyny adapts to new media. Feminist Studies, 39(2), 563-570.

Marcu, G., Kaufman, S. J., Lee, J. K., Black, R. W., Dourish, P., Hayes, G. R., \& J. Richardson, D. J. (2010). Design and evaluation of a computer science and engineering course for middle school girls. Conference paper published in proceedings of the 41st ACM technical symposium on computer science education, Milwaukee, WI.

Margolis, J., \& Fisher, A. (2002). Unlocking the clubhouse. Cambridge, MA: MIT Press.

Messner, M., \& South, J. (2011). Legitimizing Wikipedia -- How US national newspapers frame and use the online encyclopedia in their coverage. Journalism Practice, 5(2), 145-160.

Microsoft. (n.d.). A national talent strategy. Retrieved from https://news.microsoft.com/download/presskits/citizenship/MSNTS.pdf 
Mosatche, H. S., Matloff-Nieves, S., Kekelis, L., \& K. Lawner, E. K. (2013). "Effective STEM programs for adolescent girls: Three approaches and many lessons learned." Afterschool Matters, 17, 17-25.

No Ceilings Organization. (2015). It's time to unleash girls' potential in STEM. Retrieved from http://noceilings.org/stem/

NPR. (2014, October 21). What happened to women in computer science?

Retrieved from http://www.npr.org/sections/money/2014/10/21/357629765/when-womenstopped-coding

Osborne, H. (2018, March 18). What is Cambridge Analytica? The firm at the centre of Facebook's data breach. The Guardian. Retrieved from: https://www.theguardian.com/news/2018/mar/18/what-is-cambridgeanalytica-firm-at-centre-of-facebook-data-breach

Outlay, C. N., Platt, A., \& Conroy, K. (2014). Getting IT together: Linking computing intervention camps with computing careers. Conference paper published in proceedings of the 45th ACM technical symposium on computer science education, Singapore.

Paasoonen, S. (2011). Revisiting cyberfeminism. Communications: The European Journal for Communication Research, 36, 335-352.

Paling, E. (2015, October). Wikipedia's hostility toward women. Atlantic. Retrieved from http:/www.theatlantic.com/technology/archive/2015/10/howwikipedia-is-hostile-to-women/411619/

Pearson. (2015). Student mobile device survey. Retrieved from http://www.pearsoned.com/wp-content/uploads/2015-Pearson-StudentMobile-Device-Survey-College.pdf

Preece, J., \& Shneiderman, B. (2009). The reader-to-leader framework: Motivating technology-mediated social participation. AIS Transactions on HumanComputer Interaction, 1(1), 13-32.

Puchner, L, Markowitz, L., \& Hedley, M. (2015). Critical media literacy and gender: Teaching middle school students about gender stereotypes and occupations. The Journal of Media Literacy Education, 7(2), 23-34.

School Education Gateway. (2015). Computer programming and coding in schools - an emerging trend. Retrieved from

http://www.schooleducationgateway.eu/en/pub/news_events/computer_prog ramming and codin.htm

Schmidt, H. (2013). Media literacy education from kindergarten to college: A comparison of how media literacy is addressed across the educational system. The Journal of Media Literacy Education, 5(1), 295-309.

Scott, K. A., Sheridan, K. M., \& Clark, K. (2015). Culturally responsive computing: A theory revisited. Learning, Media and Technology, 40(4), 412-436. doi: 10.1080/17439884.2014.924966.

Slashdot. (2004, July 28). Wikipedia founder Jimmy Wales responds. Retrieved from https://slashdot.org/story/04/07/28/1351230/wikipedia-founder-jimmywales-responds 
Smith, M. (2013, October 16). 'Edit-a-thon' aims to fix gender inequality on Wikipedia. Huffington Post. Retrieved from http://www.huffingtonpost.com/2013/10/16/wikipedia-genderinequality_n_4109800.html

Thiry, H., Archie, T., Arreola-Pena, M., \& Laursen, S. (2015). Linkages between youth diversity and organizational and program characteristics of out-ofschool-time science programs: A mixed-methods study. International Journal of Science Education, Part B, 7(2), 121-145.

Vassallo, T., Levy, E., Madansky, M., Mickell, H., Porter, B., Leas, M., \& Oberweis, J. (2016). Elephant in the valley. Retrieved from http://elephantinthevalley.com

Volokh, E. (2017, March 17). When should courts rely on Wikipedia? Washington Post. Retrieved from https://www.washingtonpost.com/news/volokhconspiracy/wp/2017/03/17/when-should-courts-rely-onwikipedia/?utm_term $=.706 \mathrm{c} 8 \mathrm{ec} 78 \mathrm{da} 2$

Weisgram, E. S., \& Bigler, R. S. (2007). Effects of learning about gender discrimination on adolescent girls' attitudes toward and interest in science. Psychology of Women Quarterly, 31, 262-269.

Wacjman, J. (2008). Technology as a site of feminist politics. In P. Lucht \& T. Paulitz (Eds.), Recodierungen des Wissens: Stand und Perspektiven der Geschlechterforschung in Naturwissenschaften und Technik [Recoding of knowledge: State and perspectives of research on gender in the natural sciences and technology], (pp. 87-101). Frankfurt: Campus.

White, J., \& Massiha, G. H. (2016). The retention of women in science, technology, engineering, and mathematics: A framework for persistence, International Journal of Evaluation and Research in Education, 5(1), 1-8.

Wikipedia. (2016). Gender bias on Wikipedia. Retrieved from https://en.wikipedia.org/wiki/Gender_bias_on_Wikipedia

Wineburg, S., \& McGrew, S. (2016). Why students can't Google their way to the truth. Education Week, 36(11), 22, 28.

Xinhua. (2015, February 21). Finland to introduce computer programming in primary schools. Retrieved from http://news.xinhuanet.com/english/europe/europe/201502/21/c 134009013.htm

Yong, E. (2012, October 22). Edit-a-thon gets women scientists into Wikipedia. Nature. Retrieved from http://www.nature.com/news/edit-a-thon-getswomen-scientists-into-wikipedia-1.11636

Zada, J. (2011). Take this lollipop. Interactive short film. Retrieved from http://www.jasonzada.com/portfolio/lollipop/ 